\title{
The Electrochemical Behavior of Mg-Al-Zn-In-Ga Alloy as Anode Materials in Sodium Chloride Solution
}

\author{
Jiarun $\mathrm{Li}^{1,2}$, Kai Wan $^{1, *}$ and Ning Wang ${ }^{1,2}$ \\ ${ }^{1}$ Key Laboratory of Marine Environmental Corrosion and Bio-fouling, Institute of Oceanology, \\ Chinese Academy of Sciences, Qingdao 266071, Shandong, China; \\ ${ }^{2}$ University of Chinese Academy of Sciences, Beijing 100049, China \\ *E-mail: wank711011@163.com
}

doi: $10.20964 / 2017.04 .62$

Received: 24 January 2017 / Accepted: 4 March 2017 / Published: 12 March 2017

The microstructures and electrochemical behavior of Mg-Al-Zn-In-Ga alloys are investigated by scanning electron microscopy (SEM), X-ray diffraction (XRD), galvanostatic oxidation, potentiodynamic polarization and electrochemical impedance spectroscopy (EIS). Their performances as anode for $\mathrm{Mg}-\mathrm{CuCl}$ water-activated battery are also evaluated. It is found that appropriate $\mathrm{Ga}$ alloying (1 wt.\%) could promote the electrochemical properties of Mg-Al-Zn-In alloy, but over alloying (2 wt.\%) may increase the self-corrosion and decrease the discharge capability. The $\mathrm{Mg}$ $6 \% \mathrm{Al}-3 \% \mathrm{Zn}-1 \% \mathrm{In}-1 \% \mathrm{Ga}$ alloy with desirable corrosion resistance and discharge performance is a kind of promising anode materials for broadening the Mg power sources application.

Keywords: Magnesium alloy; Electrochemical behavior; Anode materials; Corrosion; Discharge

\section{$\underline{\text { FULL TEXT }}$}

(C) 2017 The Authors. Published by ESG (www.electrochemsci.org). This article is an open access article distributed under the terms and conditions of the Creative Commons Attribution license (http://creativecommons.org/licenses/by/4.0/). 